\title{
La pasión de Policarpa, de Pedro Badrán Padauí: una posibilidad para entender el pasado*
}

\author{
Jill Escandón Martínez ${ }^{1}$ \\ Universidad Internacional Iberoamericana (Puerto Rico).
}

\section{Resumen}

En el siguiente artículo nos proponemos abordar cómo, a partir de los personajes femeninos de la novela histórica La pasión de Policarpa, de Pedro Badrán Padauí, se visibiliza y re-escribe una "historia otra", alterna a los registros históricos oficiales, que desmonta la lógica de la historia colonial tradicional. Para ello analizaremos de qué manera se ficcionaliza el dominio español del siglo XIX colombiano y cómo la estrategia epistolar, entendida como un intento de aproximación microhistórica sobre este período, propone otras formas de pensar la "Historia".

Palabras clave: mujer, estrategia epistolar, microhistoria, reescritura, polifonía.

\begin{abstract}
This article attempts to show how through the female characters of the historic novel $L a$ pasión de Policarpa by Pedro Badran Padauí, an "alternate history" is visualised and re-written. It also alternates the official historic records that dismantle the logic of the traditional colonial history. To that extent, we'll analyse in which way the Spanish Colombian domain of the XIX was fictionalized, and how the epistolary strategy is understood as an attempt of microhistoric approximation on this period, proposing several ways to rethink "history".
\end{abstract}

Keywords: woman, epistolary strategy, micro-history, rewriting, polyphony

\footnotetext{
*"La pasión de Policarpa by Pedro Badrán Padauí: A possibility to understand the past"

Recibido: 1 de octubre de 2013 - Aprobado: 30 de octubre de 2013.

${ }^{1}$ Profesional en Lingüística y Literatura de la Universidad de Cartagena. Candidata a Magíster en Educación, con Especialidad en Educación Superior, de la Universidad Internacional Iberoamericana (UNINI) de Puerto Rico.e-mail: lindacartagenera08@ hotmail.com.
} 
"El arte da vida a lo que la historia ha asesinado. El arte da voz a lo que la historia ha negado, silenciado o perseguido. El arte rescata la verdad de manos de las mentiras de la historia."

C. Fuentes, Cervantes, o la crítica de la lectura, 1994.

\section{Resemantización de un género: escribiendo una "nueva historia"}

La pasión de Policarpa (2010) se asume, desde la contemporaneidad latinoamericana, como una novela histórica, adquiriendo un renovado interés que, en palabras de Badrán Padauí (2010), sirve para entender mejor ciertas tragedias del mundo moderno. Entiéndase renovado en la medida en que esta novela, si bien se nutre de toda una tradición de la novela histórica tradicional -Waverley (1814) e Ivanhoe (1819), de Walter Scott; La flecha negra (1888), de Robert Louis Stevenson y El último mohicano (1826) de James Fenimore- y de la novela epistolar -Cornelia Bororquia (1799), de Luis Gutiérrez, Pepita Jiménez (1874), de Juan Valera y Mrs Caldwell habla con su hijo (1953), de Camilo José Cela-, va mucho más allá, re-pensando la realidad social americana, en especial sus discursos fundacionales, desde el lenguaje que construye los discursos de sus personajes. Esta preocupación, que podría leerse como resemantización del género, lleva a La pasión de Policarpa a dialogar con otros géneros (o subgéneros) como la epístola y el relato onírico. A esto Bajtín lo llama intertextualidad. El narrador pone en perspectiva múltiples discursos (epístolas, relatos oníricos, diálogos y narraciones) en un mismo plano verbal, polifónicamente.

A lo largo de la trama se intercalan así sueños y cartas que "cortan" el hilo de la narración, dirigidas a un cronista sin nombre o personaje velado -no aparece nunca como personaje explícito; apenas es aludido en las cartas- que funciona como el vehículo que permite que la historia sea contaba, sin ser él la voz narradora de la novela. Es el Cronista quien se encarga de realizar las investigaciones, entrevistas y escrutinios con las mejores amigas de Policarpa -Barbarita Cuervo, Andrea Ricaurte y Trinidad Almeyda- para desentrañar los hilos de amores, traiciones, guerras y odios entre Policarpa Zalabarrieta y Alejo Zabaraín. ¿Qué implicaciones, sin embargo, tiene el hecho de que sea un cronista el destinatario de las epístolas? ¿Por qué Badrán Padauí ficcionaliza este oficio al interior de su novela? 
Durante el siglo XIX, la figura del cronista se asocia a la recopilación y redacción de acontecimientos de interés histórico con voluntad de veracidad. Pretensión que lo sitúa -para esta misma época- al mismo nivel de los historiadores y periodistas. A la par del desarrollo de la historia como ciencia, este oficio fue adquiriendo funciones más claras y específicas. En efecto, la búsqueda de la "verdad", ligada a las pretensiones de objetividad exigidas durante esta centuria, llevó a una evolución del género: se comenzó a dar prioridad al objeto (hecho histórico en sí mismo) antes que al sujeto y sus apreciaciones personales ${ }^{2}$.

¿Por qué entonces el cronista de La pasión de Policarpa, en su afán por construir una historia "veraz" -como debería ser su propósito-, sustenta sus averiguaciones en los testimonios de tres mujeres, en una sociedad donde los sujetos femeninos eran marginados de los asuntos de la República? El hecho de que Badrán Padauí ficcionalicé el oficio de cronista al interior de su novela y que, además, su labor se legitime desde voces femeninas significa, entre otras cosas, 1) que el cronista trasgrede los códigos que, en una época donde las mujeres no tenían acceso a la escritura pública, se impusieron a su labor y 2) que la verdad que se funda da prioridad a lo ínfimo, doméstico y privado: territorio cedido "naturalmente" a lo femenino, para comprender mejor los grandes acontecimientos públicos, en su mayoría masculinos, abanderados por la historiografía oficial.

Sólo así es posible entender por qué la "Historia" ha ignorado ciertos acontecimientos y ha resaltado otros, pues todo responde al conjunto de fuerzas (políticas, económicas y sociales) que se ponen en escena a la hora de escribir la historia: "No quisiera yo recordar hechos tan luctuosos pues aun historiadores y cronistas los ignoran o apenas los mencionan" (Badrán, 2010: 37). El Cronista de La pasión de Policarpa trasgrede los patrones impuestos a su oficio y se aventura a escribir una "nueva historia". Una que ahonde en relación a lo que sus colegas de pluma, los cronistas oficiales, han ignorado debido a los requerimientos gubernamentales. Visto así, estas apreciaciones nos llevan a confrontar desde la ficción literaria conceptos como micro y macrohistoria. En especial, cómo esta última, en cierto modo "oficial" y masculina, ha cometido ciertos "descuidos".

\footnotetext{
${ }^{2}$ Es así como, por ejemplo, los cronistas coloniales tuvieron que distanciarse de lo que hoy conocemos como "Crónicas de Indias": relatos, a medio camino entre la realidad y la fantasía, donde se describe el choque de culturas que se produjo cuando los primeros colonizadores llegan a territorio americano. Aquí, América es presentada desde categorías subjetivas como lo exótico, maravilloso y asombroso y, sus habitantes, los indígenas, son considerados como seres primitivos, irracionales y supersticiosos.
} 
Desde la microhistoria se busca estudiar acontecimientos y personajes que, de no ser así, pasarían inadvertidos (amoríos, epistolarios, comentarios, reuniones sociales, entre otros). Esta disciplina histórica -con representantes como Giovanni Levi, Carlo Ginzburg y Carlo María Cipolla- se acerca desde una perspectiva renovada a los hechos del pasado: las corrientes historiográficas oficialistas se habían basado generalmente en una concepción macro-histórica de los hechos, limitándose a narrar o interpretar grandes sucesos, procesos, hechos, o personajes históricos, pero sin interpretar desde la pequeña escala las realidades sociales, cambiantes o permanentes, que son la base en torno a la cual gira la historia. La microhistoria, para Giovanni Levi (1990), citado por María Luz González (2000), es "un análisis de la realidad histórica que magnifica la escala de observación -similar a la utilización de un microscopio- para ver los detalles que se obviaron en la mirada normal. Es necesaria allí donde ha fallado la macrohistoria para identificar los problemas reales de la dinámica social o ha caído en tautologías y preestablecido modelos de referencia” (129).

La tendencia macrohistórica, por su parte, podemos rastrearla hasta Heródoto de Halicarnaso - padre de la historiografía occidental junto a Tucídides-, quien en el exordium de los Nueve libros de la historia, publicado en el siglo III o II a. C. , sienta las bases de una historia pública, que registre grandes acontecimientos: "la publicación que Heródoto de Halicarnaso va a presentar de su historia, se dirige principalmente a que no llegue a desvanecerse con el tiempo la memoria de los hechos públicos de los hombres, ni menos a oscurecer las grandes y maravillosas hazañas, así de los Griegos, como de los bárbaros" (2000: 13). En las líneas de Heródoto es posible rastrear cómo la historia originariamente es pensada para resaltar los valores agonísticos masculinos, sus grandes hazañas públicas y su verificación colectiva. No obstante, frente a esta concepción del pasado, se opone una tendencia que busca resaltar los pequeños acontecimientos, propios de la esfera privada, que suelen ser valorados desde su intranscendencia histórica. Perspectiva histórica que asume, en esta misma línea, Juan Rodríguez Freyle, quien a "la husma de enredos e infidelidades domésticas, tuvo el cuidado de explicar la naturaleza de la verdad histórica, que ni es patrimonio de unos pocos privilegiados, ni conviene dejar en la penumbra acontecimientos desdorosos para la honra" (Freyle, 1963: 20).

Así, el hecho de que en La pasión de Policarpa se intercalen cartas o se conceda la voz a ciertos personajes femeninos para validar la historia, opera como una estrategia narrativa que asume las misivas como instrumentos testimoniales y clarificadores del pasado novelado. Si 
estas cartas no existieran, probablemente habría más de un aspecto oscuro e inaccesible para el Cronista; se mueven en el territorio de la intimidad escrita: cargadas de una dimensión personal y emotiva que interpela a su destinatario, con un halo perturbador, en la medida que pueden revelar detalles significativos no historiados.

\section{Entre la villa y la ciudad: trazos de una biografía}

La pasión de Policarpa, entendida como un intento de aproximación microhistórica, versa sobre las peripecias de un grupo de jóvenes patriotas, entre los cuales se cuenta Policarpa Zalabarrieta, que lucha por defender la autonomía y libertad de la Nueva Granada. El desarrollo de los acontecimientos se mueve entre tres momentos y espacios básicos: el primero, que se desarrolla en la ciudad de Santafé, marcado por la muerte de los padres de la protagonista; el segundo, en la villa de San Miguel de las Guaduas, período en el que empieza a realizar sus primeros trabajos de insurgencia comunera, y el tercero, que tiene lugar -nuevamente- en la capital del país, donde, luego de aceptar el llamado a la aventura heroica hecho por el General Bolívar, decide entregarse por completo a la causa patriota, sirviendo como espía del ejército real español. Analizaremos a continuación cada una de estas etapas, teniendo en cuenta la forma cómo se entrelazan y cómo permiten comprender el forjamiento del carácter heroico de la protagonista.

La primera de estas etapas, como hemos afirmado, marca el período de la adolescencia de Policarpa, quien, junto a sus padres José Joaquín Zalabarrieta y Mariana Ríos, y sus hermanos Bibiano, Catarina y José María de los Ángeles, arriban a la capital -en la novela no se explican las razones de este desplazamiento-. Allí deberán enfrentar la epidemia de viruela que azota a la ciudad y que termina llevándose la vida de su madre y de su padre. Policarpa se asumirá como huérfana bajo la tutoría de un amigo de su padre, el barbero Bernabé Rodríguez Bautista, quien la enseña a leer y a escribir -instrucción poco común para las mujeres de la época-:

\footnotetext{
Quiero enseñarte a leer y a escribir, aunque no sea costumbre que las mujeres de este Reino lo hagan. Asílo disponen algunos sacerdotes y hay padres de familia que juzgan conveniente dejar en tinieblas a sus hijas, no vaya a ser que conociendo las letras, puedan enviar cartas y mensajes a quienes las requiebran (48).
}

Aunque su padre no puede legarle ni a ella ni a su hermana una buena dote, procura dejarlas bajo la autoridad y cuidado de una figura 
conocida. Pero no es sino hasta la muerte del barbero, ejecutado tres años después bajo la acusación de conspiración y herejía, que Policarpa y sus hermanos deciden regresar a la villa de San Miguel de las Guaduas. Este retorno, que se constituye en el segundo momento determinante para el desenlace de los acontecimientos, marca un antes y un después en la vida de Policarpa. Es en la villa de San Miguel de las Guaduas donde la protagonista decide aceptar el llamado a la aventura y asumir su destino heroico, tal cual lo manifestaba su padre: "[...] ella es distinta, compadre, no es como las otras" (47).

Policarpa da sus primeros pasos en la insurgencia colaborando con algunos jefes llaneros que apreciaban sus servicios como informante: "[...] a no ser por los frascos de aguardiente, las arrobas de azúcar y las cascarillas que ella hurtaba de la tienda para enviarlas a los tumultuados de Tocaima [...], ningún servicio había prestado a la libertad" (113). No obstante, si algo logra llamar la atención a la protagonista es cuando, a la llegada de las tropas de Bolívar a la villa, en una fiesta organizada por Doña Soledad Pérez -viuda del regidor del pueblo-, sostiene una conversación con el General que inquieta su espíritu: "Una joven como usted no ha nacido para los montes pero tampoco para los encajes. Pronto encontrará la manera de prestar grandes servicios a nuestra causa y creo que sólo podrá hacerlo en Santafé" (23-4).Estas palabras se convertirán en el motor que la anime a regresar a la capital, una empresa en la cual colaboran tanto su hermana Catarina, quien la ayuda a conseguir el pasaporte, y su hermano José María de los Ángeles, quien establece contacto con Doña Andrea Ricaurte de Lozano para que la aloje como su protegida.

Ya en la capital, Policarpa, utilizando su oficio temporal como costurera, logra establecer contacto con importantes damas patriotas de la capital: Doña Eusebia Caicedo, viuda de Valencia, Doña Beatriz O’Donell de Pombo, Doña María Matea Zaldúa Martínez de la Herrans y Doña María Tadea Lozano, entre otras. Es así como se convierte en espía de los godos fieles a Su Majestad e infiltra el estado de fuerzas de los batallones reales a través del escribiente José María Arcos, patriota que sirve en el batallón del Tambo. La protagonista tendrá que recurrir a una identidad enmascarada que le permita moverse entre los godos y patriotas con total naturalidad, tal cual lo advertía Doña Andrea: "en tiempos de guerra conviene llamarse de varias maneras" (117). Para sus clientes será Gregoria, para los amigos de la causa, Policarpa. Pese a los esfuerzos realizados, es descubierta, entre otras razones debido al triángulo amoroso desatado a raíz de que el escribiente José María Arcos se enamora de ella. Policarpa finalmente es condenada al fusilamiento junto con Alejo Zabaraín, 
Francisco Arrellano, José María Arcos y otros patriotas, por su insurrección contra la Corona española.

En la novela de Badrán Padauí prevalece un estilo directo -el narrador deja que se escuche o lea directamente lo que los personajes dicen, piensan, o hacen-, si bien (o por el mismo hecho) el narrador omnisciente se comporta como una especie de conciencia divina que lo sabe y conoce todo. De igual forma, la novela presenta un ritmo intercalado que ficcionaliza los años comprendidos entre 1797 y 1828, período que no se corresponde con un tiempo cronológico lineal, pues la narración hace saltos temporales que van del presente al pasado y posteriormente al futuro. Esto requiere que el lector relea lo visto para entender ciertos hechos que luego han de explicarse con mayor detenimiento. Así, por ejemplo, la novela inicia cuando el batallón patriota de Bolívar llega a la villa de San Miguel de las Guaduas, en diciembre de 1814, y la viuda del regidor del pueblo Doña Soledad Pérez- solicita a Policarpa sus servicios como mesera para el baile que se les prepara a los insurgentes (oficio que la protagonista había aprendido años atrás en la ciudad de Santafé):

[...] doña Soledad Pérez viuda de Acosta encareció los servicios de la joven Apolonia, tan diligente y tan diestra en las artes de servir los entremeses y los vinos de Castilla, como que los había aprendido en casa de reputadas damas santafereñas [...] Apolonia había servido en casa de algunas damas santafereñas que la trataron como una hija, [...] si hasta la enseñaron a bailar chaconas, contradanzas y zarabandas [...] (12-3).

Desde este acontecimiento, la narración hace un salto a la infancia $\mathrm{y}$ adolescencia de la protagonista, y es entonces cuando se narran la muerte de sus padres, su tutoría a cargo del barbero Bernabé Rodríguez y su regreso a la villa, para, posteriormente, relatar cómo Policarpa se reencuentra con Alejo Zabaraín, sus coqueteos con el escribiente José María Arcos, su vinculación a los pelotones insurgentes como costurera-espía y su ulterior fusilamiento. Encontraremos incluso en la narración situaciones que sólo pueden ser entendidas a la luz de las cartas que se introducen a lo largo de la novela, como, por ejemplo, el hecho de que el padre de Policarpa, en los días de su juventud, también se enlistara en las tropas de insurgencia comunera, lo cual se confirma en una de las cartas que Doña Andrea Ricaurte de Lozano dirige al Cronista, al referirse al carácter de la protagonista: 
[...] Cantaba, sobre todo en las mañanas, y sus modales eran muy sanos y virtuosos, como que había crecido en una familia profundamente religiosa y de corazón patriota. Esto le venía, dicen, de su padre, que fue uno de los que acompañó a José Antonio Galán hasta las Guaduas y Zipaquirá (142).

Este último aspecto -el hecho de que algunas situaciones sólo pueden ser entendidas a la luz de las cartas- explica una de las diversas funciones que adquiere la epístola al interior de la novela (confirmar datos) y nos ayudará a entender -en los siguientes apartados de nuestra investigación- en qué medida influyen las cartas introducidas para que La pasión de Policarpa pueda leerse como una re-escritura del pasado en clave intimista femenina.

\section{Re-escritura del discurso historiográfico oficial: una mirada intimista}

Badrán Padauí, a partir de los testimonios mínimos e íntimos de sus personajes -aquellos que tuvieron que ver con los procesos emancipadores de la Nueva Granada-, re-escribe la historia independentista colombiana. Estos "testimonios" se nutren de la experiencia vital de seres que, en medio de crueles matanzas y guerras, peleaban, conspiraban, espiaban y defendían ideales como la justicia, la equidad social y la libertad. La pasión de Policarpa construye así una re-lectura del pasado. La "novela histórica de fines del siglo XX", como señala Pons (1999), "se caracteriza por la relectura crítica y desmitificadora del pasado a través de la reescritura de la historia. En este proceso, algunas novelas obstaculizan la posibilidad de conocer y reconstruir el pasado histórico; otras recuperan los silencios o el lado oculto de la historia, mientras que otras presentan el pasado histórico oficialmente documentado y conocido desde una perspectiva diferente, desfamiliarizadora" (140).

Lo expuesto por Pons, nos permite relativizar las verdades históricas y cuestionar desde la ficción literaria la "historia oficial", "tradicional" o "monumental", que se detiene principalmente en los grupos de élite (social, política o económica), con el fin de mantener las relaciones de dominación ${ }^{3}$. Esta relativización se evidencia en la

\footnotetext{
${ }^{3}$ Desde esta historia se le da importancia a los llamados héroes o a la vida institucional de los gobernantes y, finalmente, se cree que existe una verdad única. En oposición a esta concepción, surge la historia efectiva o crítica que se realiza a partir de la vida de las personas que construyen verdaderamente la vida social. Esta es la historia de los explotados, de los negros, de los indígenas, de los trabajadores, de los LGTBI (lesbianas, gay, transexuales, bisexuales e intersexuales), de las mujeres, de los niños, de las feministas, de los jóvenes, de los afro-descendientes.
} 
novela, por citar un ejemplo, en la constante recurrencia al diálogo para dejar entrever los pensamientos y modos de concebir la vida de los exiliados, quienes generalmente aparecen con voz propia (a través del empleo de estrategias discursivas como la conversación, la epístola, la anécdota e incluso los recuerdos, como la construcción de un discurso alternativo al histórico).

Para efectos de nuestra investigación analizaremos especialmente dos estrategias discursivas: el diálogo y la epístola (esta última a la cual se dedicará con mayor profundidad el siguiente apartado), determinando en qué medida completan o se oponen al discurso histórico oficialista desde tres niveles: a) la imagen del Libertador, Simón Bolívar, b) la representación de las tropas patriotas y c) la descripción de la guerra. En el primer nivel,el Libertador es ficcionalizado como un "caníbal", tachado y excomulgado por los sacerdotes, asociado a violaciones, desmanes y amenazas. Tal vez por ello el cuñado de Policarpa, Domingo García, se opone a que ella sirva en la fiesta que se hará en su honor, arguyendo que ese general caraqueño:

[...] albergado y agasajado en casa de un noble caballero castellano, no tuvo reparos en seducir y desflorar a la hija de su huésped, doncella de catorce años, inocente y bella como un lirio, y al día siguiente, el bellaco abandonó la casa, luego de amenazar de muerte al padre de la mancillada, la que enloqueció a las pocas semanas, hombre cobarde y miserable ese general [...] (13).

Los adjetivos utilizados para referirse al general son "cobarde" y "miserable", atributos opuestos a las virtudes que, según los discursos oficialistas, cultivó Bolívar, quien es descrito, por ejemplo, por William Hernández Ospino, historiador y escritor Colombiano, miembro de la Academia Colombiana de Historia, por sus acciones políticas en la causa emancipadora y reconocido como el "Hombre de América", destacada figura de la Historia Universal. Así lo reconoce también Pablo Neruda (1950), en su poema "Un canto para Bolívar": "Pero hacia la esperanza nos conduce tu sombra,/ el laurel y la luz de tu ejército rojo/ a través de la noche de América con tu mirada mira./ Tus ojos que vigilan más allá de los mares,/ más allá de los pueblos oprimidos y heridos,/ más allá de las negras ciudades incendiadas,/

Esta es la historia que reconoce la pluralidad del mundo, la acepta y la potencia sin moralismos, ni discriminaciones de tipo racista, ni fascista, ni nazista, ni xenófobo, ni sexual, ni clasista. Para esta historia no existe una verdad única, sino que existen verdades construidas entre todos, con las voces de los otros, no con una sola voz. 
tu voz nace de nuevo, tu mano otra vez nace:/ tu ejército defiende las banderas sagradas:/ la Libertad sacude las campanas sangrientas,/ y un sonido terrible de dolores precede/ la aurora enrojecida por la sangre del hombre". Esta imagen, sin embargo, difiere totalmente de la que, según la novela, Bolívar se había encargado de cultivar entre sus conciudadanos: hombre soberbio, casi comparable a los dioses, acostumbrado a actuar sin ninguna clase de escrupulosos. Incluso su apariencia física es cuestionada, si bien en diferentes términos a la de una entidad maligna:

- ¿Ese es el general? -preguntó un tanto decepcionada cuando lo vio.

Ni cachos ni rabo de diablo, como le habían dicho, sólo un hombre de cabellos desordenados y ya entradas en su cabeza, sin apostura de caballero y sobre todo mezquino de cuerpo, con una nariz demasiado grande y ojos de gavilán, eso sí, qué mirada la que tenía (15-16)

La reacción de Policarpa resulta bastante gráfica; nos permite inferir que, aunque el General pretendía darse a conocer por su "apostura de caballero", la realidad era otra. La protagonista nos describe a un hombre común y corriente, nada apuesto ni galante, alejado de la estela mítica y benevolente en la que lo había envuelto. Es de reconocer entonces, en La pasión de Policarpa, a un Simón Bolívar carnavalizado: sus valores "heroicos" han sido invertidos o rebajados ${ }^{4}$. El Libertador se muestra como un ser indolente, sanguinario. Podemos decir así que esta novela continúa la línea de escritores como Gabriel García Márquez, con El general en su laberinto (2005) y Fernando Cruz Kronfly, con La ceniza del Libertador (2008), donde se desmitifica la figura de Bolívar y anticipa La carroza de Bolívar (2012), de Evelio Rosero, donde se narran los desmanes que los libros no reportan de Simón Bolívar, entre ellos, la navidad negra de Pasto $(1822)^{5}$. Vemos, pues, cómo desde el discurso literario se empieza a perfilar la construcción de un discurso alternativo al oficial en el que primen

4 "El carnaval no se contempla ni tampoco se representa, sino que se vive en él según sus leyes mientras éstas permanecen actuales, es decir, se vive la vida carnavalesca. Esta es una vida desviada de su curso normal, es, en cierta medida, la "vida al revés", el “mundo al revés".” (Bajtín, 1993: 172-173).

${ }^{5}$ El tremendo odio que el Libertador Simón Bolívar sentía contra la ciudad de Pasto y sus moradores, por el apoyo a España, se desencadenó en la navidad de 1822, cuando las tropas patriotas, al mando de Antonio José de Sucre, se tomaron la ciudad y protagonizaron uno de los más horripilantes episodios de la guerra de la Independencia. Fue una verdadera orgía de muerte y violencia desatada, en la que hombres, mujeres y niños fueron exterminados, en medio de los más incalificables abusos. 
las apreciaciones subjetivas de los personajes (o narradores) antes que el supuesto objetivismo de los relatos históricos tradicionales.

En lo que respecta al segundo nivel de análisis, correspondiente a la representación de las tropas, podemos decir que son ficcionalizadas de modo similar a su comandante, el general Bolívar. Los rebeldes patriotas aparecen como seres hediondos, desalmados, capaces de cometer toda clase de oprobios en nombre de la libertad. Cuando las tropas llegan a la villa de San Miguel de las Guaduas, por ejemplo, las damas del pueblo se ven en la penosa necesidad de disimular: "[...] la molestia que les causaba el grajo de aquellos guerreros, pues por mucho que las esclavas los hubieran restregado con estropajo, en los barriles del convento de Nuestra Señora de los Ángeles o en las frescas aguas del río San Francisco, no podían conjurar ni el cutre ni los sudores ni la hediondez del estiércol de bestias que guardaban los pliegues de los uniformes" (17).

Lejos de constituirse en hombres fieles a sus ideales revolucionarios, se decía que la tropa insurgente "era una mala tropa que además cambiaba de bando al vaivén de las victorias. Ahora eran patriotas. Pero si Sámano o Aymerich vencían, ellos se convertían en furiosos monárquicos (96-7)". Lo anterior se evidencia, por ejemplo, en el siguiente poema que escribe el oficial de pluma José María Arcos, durante el tiempo que es retenido en la cárcel: "No quiero la vida,/ prefiero la muerte,/ lamento la suerte/ de la patria mía” (107). El hablante lírico ve la muerte como la única salida posible frente a la situación caótica que vive su patria. Arcos, condenado a servir en el batallón del Tambo, luego de recibir un indulto, se presenta como un hombre temeroso y frágil que prefiere la muerte antes que luchar por la libertad de sus conciudadanos. Imagen que difiere de la acostumbrada glorificación en la que los hombres -y los patriotas- son el estandarte de valores guerreros como la valentía, la fuerza y la nobleza: "No parecía este escribiente distinto a los otros rebeldes con los que él había lidiado, hombres cobardes, débiles y sin honor militar, más imprudentes que valerosos" (328-9). Muchos insurgentes, así mismo, siembran el terror en poblaciones inocentes que deberán sufrir las consecuencias de la guerra, como sucedió con la hermana del sargento Iglesias, soldado fiel a su Majestad:

Unos años antes, oficiales desalmados al mando de un tal Pedro Montúfar, en cuyo corazón moraba Lucifer, no dudaron en incendiar las aldeas cercanas a Pasto, luego de cometer violaciones, tropelías y toda clase de impiedades. Su pequeña hermana de doce años padeció el desaforado entusiasmo revolucionario que pregonaba la libertad e independencia. 
Llegó tarde para impedir el oprobio al que la sometió uno de los capitanes rebeldes, poseído por el fuego francés. Entonces sólo cenizas quedaron en la choza que había sido de su madre y en la aldea, una cosecha de pescuezos degollados (209).

La guerra independentista, en un tercer nivel, es mostrada en su crueldad y lejos de ser imaginada como una epopeya romántica, la Independencia se presenta como aquel período de la historia de Colombia caracterizado, siguiendo a Walter Broderick (2010), por matanzas atroces y guerras civiles sucesivas, motivadas no siempre por lo más altos ideales.

Boves, un rubio contrabandista asturiano idolatrado por mulatos, zambos y llaneros, cobro fama de feroz, persiguió a los rebeldes y degolló niños y mujeres por toda la capitanía de Venezuela. El coronel Arismendi, entre tanto, por orden del Libertador, alanceó a ochocientos peninsulares inocentes, presos en cárceles de la Guaira y Caracas. En la sangrienta competencia de atrocidades, cada oficial se empeñaba en superar la barbarie de su enemigo (146).

La pasión de Policarpa se aparta de la exaltación festiva, aparénteme propicia, por su fecha de publicación, para las conmemoraciones del Bicentenario de la Independencia. La "historia de nuestras guerras pesa", reconoce Badrán Padauí (2010), y también pesan los conflictos no resueltos de la independencia". La novela "trata de poner en relieve unos hechos, iluminarlos, para entender el presente, que es también horroroso, con guerras que se relacionan con esas que nunca acabaron". La guerra es vista pues como una competencia que embrutece y sus actores son ficcionalizados como seres soberbios, malolientes, escandalosos, sanguinarios y carentes de urbanidad y buenos modales en la mesa. El despotismo se presenta de lado y lado: tanto como por los soldados realistas como por los rebeldes patriotas. Los primeros, porque fusilaban, decapitaban y exiliaban a todos aquellos que se atrevieran a pensar diferente, y los segundos, porque, entre otros excesos, reclutaban muchachos para la causa, cargando joyas, víveres y dinero de aquellos pueblos en los cuales eran alojados.

Cabe aclarar entonces que la re-escritura del pasado en la novela de Badrán se realiza bajo una lente subjetiva, pero legítima, en voz de sus protagonistas, exponiendo cada hecho al criterio de los participantes desde sus dimensiones psicológicas, físicas, morales e intelectuales. En este "intimismo" narrativo se construirá explícitamente la(s) historia(s) desde el sujeto y no desde el objeto, como es pretensión de 
la historiografía oficial o del historicismo positivista. En esa medida, ningún hecho es "falso", pero tampoco "verdadero": cada perspectiva es valedera desde el punto de vista desde el cual se contempla. La narración se auto-sostiene -más allá de las presunciones del "objetivismo" historiográfico- en los diálogos, recuerdos y cartas de personajes que, como afirma Andrea Ricaurte en una de sus misivas, padecen las imperfecciones propias de la memoria (141).

Los personajes femeninos de la novela, en este sentido, no se muestran como alineados del tiempo y el espacio -el tiempo y el espacio de una sola historia-, sino que, más bien, se descubren desde el dolor y la agonía, rompiendo en su caso con el ideal impuesto por el orden patriarcal: castidad, sumisión, desconocimiento y no violencia. Al contrario, son ficcionalizadas como excelentes estrategas, prestas al auxilio de la causa y como ardientes amantes. Es más, el mismo Sámano reconoce su peligrosidad: "Guardaos de la mujeres, teniente, son más peligrosas que un ejército" (353). De este modo, el discurso literario, trabajando sobre sujetos femeninos, "puede servir para hacer 'justicia', al convertir personajes marginalizados de los textos oficiales en héroes novelescos" (Aínsa, 1997: 116).

Tal re-interpretación es asumida por Badrán Padauí desde la certeza de que, si bien el papel de las mujeres en las gestas independentistas ha sido poco estudiado, la ficción literaria puede convertirse en el vehículo que posibilite la invención, fundación y re-construcción de un nuevo pasado: “[...] la ficción no sólo 'reconstruye' el pasado, sino que, en muchos casos, lo 'inventa', lo 'funda', al darle una 'forma' y un 'sentido' ", permitiéndonos advertir la "complejidad histórica, muchas veces simplificada, cuando no reflejada en forma reductora y maniquea en el discurso político, histórico o ensayístico [...]" (Aínsa, 1997: 112-113).

\section{De la mujer y la estrategia epistolar: la otra historia de Barbarita Cuervo y Andrea Ricaurte}

En La pasión de Policarpa encontramos un conjunto de diez cartas apócrifas que pueden clasificarse como "cartas informales": su estilo predominante es coloquial y están permeadas de un fuerte tono informativo. Es más, el corpus epistolar ofrecido por la novela -bastante módico y de limitada variedad- utiliza un lenguaje que recrea el castellano decimonónico como estrategia de verosimilitud del relato. En primer lugar, las cartas son pocas y forman elementos dispersos, cuya presencia pareciese no estar vinculada con la técnica misma de la narración novelesca. En segundo lugar, todas las cartas son breves (entre una y dos hojas), de tono afectivo y amigable. Y 
por último, constituyen un material epistolar específico (tanto en forma como en contenido) que versa básicamente sobre dos temas principales: los amoríos de Policarpa y Alejo Zabaraín y la guerra entre godos y patriotas.

Como una suerte de preludio al análisis, presentaremos un breve recuento de las cartas que se escriben en la novela, reuniéndolas en dos grandes grupos. El primero encierra el conjunto de cartas escritas por Barbarita Cuervo y Andrea Ricaurte, las mejores amigas de Policarpa, dirigidas al Cronista: son siete cartas que intentan responder preguntas puntuales que éste les realizó en comunicaciones anteriores (de las que el lector nada conoce). Tienen como objetivo principal prestar auxilio al Cronista, en relación con hechos puntuales sobre la guerra entre godos y patriotas, los días del terror y los amoríos del alférez Alejo Zabaraín y Policarpa Zalabarrieta.

El Cronista es el destinatario velado de la misivas, mostrando un marcado interés por re-construir los acontecimientos pretéritos y preguntándose por lo que "verdaderamente" sucedió. Esta figura debemos recordarlo- no es el narrador de la novela, aunque gracias a sus averiguaciones es posible construir el documento: el narrador omnisciente puede así, además de indagar y reflexionar sobre el pasado, atribuir a Barbarita Cuervo y Andrea Ricaurte el poder de "corregir" la historia a partir de sus propios testimonios de lo acontecido. En las cartas pertenecientes al primer grupo abundan indicaciones afectivas referidas al Cronista: suelen utilizarse expresiones como "querido cronista" o "estimado cronista", que denotan cierto aire de cercanía, frescura y familiaridad en el discurso. De lo cual se infiere que entre él y las autoras de las cartas existe una amistad consensuada. Asimismo, se hace evidente el empleo de fórmulas como "Me pregunta usted", "Usted no puede olvidar que", "Para el cabal entendimiento de la historia que usted narra, debo recordarle que", "debo aclararle entonces que", "déjeme decirle algo" y "no sobra recordar que", que insisten en la re-construcción subjetiva de un pasado que debe, necesariamente, ser mediatizado y "supervisado" por el lente femenino.

En lo que respecta al segundo grupo de cartas, está constituido por tres misivas escritas por el teniente Manuel Pérez Delgado, los oidores Juan Jurado y Laínez y Francisco de Mosquera y Cabrera y el Comandante General Juan Sámano, respectivamente. A diferencia de las cartas anteriores -que dividen capítulos-, estas están inmersas al interior de la trama argumentativa de la novela, y suelen restringirse 
a cumplir protocolos sociales, administrativos y militares propios a la Nueva Granada de los siglos XVIII y XIX.

Nuestro análisis centrará su atención en las cartas pertenecientes al primer grupo, pues son estas las que muestran un marcado interés por la indagación histórica de ciertos acontecimientos y situaciones. De allí que lo primero que debemos subrayar es el hecho de que en todas las epístolas seleccionadas existe una fuerte preocupación por indagar y re-construir el pasado, pero -y esto resulta realmente importante- reconociendo que es una construcción discursiva particular. Esto es, un relato parcializado, subjetivo y relativo, expuesto a olvidos e imperfecciones propios de la memoria humana, como logra apreciarse en el encabezamiento de la primera carta incluida en la novela, desde la voz de Barbarita:

No había pensado yo que un cronista tan respetable como usted se ocupara de los hechos que enlutaron esta capital ha mucho tiempo y, si la memoria me auxilia, trataré de responder en esta carta a las preguntas que usted me hace, bien con las imperfecciones que siempre podrán hallarse en los escritos de un mujer que aunque muy curiosa de la verdad nunca se ha ejercitado en menesteres históricos. (36).

El Cronista pregunta sobre aquellos sucesos que desconoce, intentando completar su investigación con los informes oportunos de dos amigas de la protagonista: Barbarita Cuervo -actriz de teatro- y Andrea Ricaurte de Lozano -dama que la aloja como su protegida en Santafé-. Acontecimientos que tuvieron lugar "ha mucho tiempo", lo que implica que existió una mediación temporal que dificulta los recuerdos de los personajes. En esta tarea son vitales sus cartas, puesto que ellas, intentando responder los interrogantes de quien se muestra como contemporáneo suyo, hacen uso de sus "deshilvanados recuerdos", advirtiendo siempre que ellos son poco confiables, defectuosos: "Tal vez no sea capaz esta humilde servidora de prestar el auxilio que sus trabajos requieren pero, visto que mis informes U. los juzga invaluables para narrar esta historia, procuraré referir algunos de mis deshilvanados recuerdos." (141).

De hecho, las autoras de las cartas manifiestan en reiteradas ocasiones su incapacidad para realizar la labor investigativa que el Cronista les ha encomendado. Reconocen que su conocimiento es limitado, debido entre otras cosas a las condiciones sociales para lo femenino en una época donde el acceso a la escritura, ya fuera pública o privada, era un hábito poco cultivado entre las mujeres -situación que se reitera en la novela, cuando el teniente Francisco Javier Leal se 
refiere al hecho de que Policarpa supiera leer y escribir: "en verdad es difícil creer que una simple costurera cultive tan rarísima virtud" (381) - pero también porque, durante la colonia, el rol público de la mujer se limitaba exclusivamente a acompañar al marido e ir a Misa.

Barbarita Cuervo y Andrea Ricaurte, lejos de reconocerse como "historiadoras", premeditan sobre el propio ejercicio revisionista que ejecutan, e incluso piden excusas a sus posibles lectores por los desvaríos que puedan contener sus relatos: "Por lo tanto ruego a usted y a sus lectores disculpar los defectos que en el curso de este trabajo adviertan, en atención a la buena fe con que los asumo" (36), denotando, por un lado, el imaginario dominante y autoasumido sobre la feminidad, pero, por otro, al encontrarse en cierto modo al margen del discurso oficial sobre la historia y su retórica, posibilitando otras formas de conocer. Tal como se aprecia en el cierre de la primera carta de Barbarita: "No deje usted de enterarme del resultado de sus averiguaciones y tampoco de enviarme los manuscritos sobre esta historia de Alejo y Policarpa, que yo podré añadir lo que a usted le haga falta y quitar todo lo que se aparte de la verdad" (38).

Barbarita Cuervo, como puede apreciarse en la cita anterior, cree en un criterio de "verdad fiel", pero este no se sustenta en el juicio de historiadores ni cronistas, sino, antes bien, se respalda en la experiencia de los sujetos que vivieron en carne propia los acontecimientos por los cuales se indaga. El criterio de veracidad de la historia que se cuenta en La pasión de Policarpa está certificado por la prioridad que en la novela se otorga a lo que los personajes vieron, oyeron y presenciaron. A este tipo de "verdad" se refieren las autoras: "Ya que muchas otras personas han querido falsear estos tristes acontecimientos, es mejor que un cronista veraz como usted los entregue a la posteridad tal y como sucedieron. Protagonista como fui de esa infausta noche le referiré algunos otros hechos que la antecedieron" (365. Las cursivas son nuestras). Es más, en algunas ocasiones se alude al gremio de los historiadores y dramaturgos, subrayando que muchos de ellos han descuidado detalles significativos de la historia: "Para mí tengo que a la Providencia le complace burlarse de los hombres, de sus sueños y de sus propósitos, porque muchas veces los detalles juzgados como insignificantes determinan el curso de una vida y de una historia como esta que se cuenta ahora, la de los desgraciados amores de Policarpa Zalabarrieta y Alejo Zabaraín. [...] Y ese mismo descuido lo han cometido muchos historiadores y dramaturgos" (322).

Cuervo y Ricaurte se convierten entonces en "correctoras de estilo" del proyecto editorial de un cronista anónimo. Entiéndase 
correctoras, pues, si bien el crédito del documento final recae sobre el Cronista, tienen la función de hacer corresponder las investigaciones de éste último con sus criterios de "verdad fiel", tal cual veíamos con anterioridad. Editarán los manuscritos finales, añadiendo y quitando lo que crean pertinente y necesario, considerando que ellas también tienen el "poder" de contar hasta donde deseen. Su facultad para influir sobre las averiguaciones del Cronista es tal que pueden obviar, menospreciar y suprimir detalles de los acontecimientos: "Muchas otras cosas por las que usted pregunta no podré respondérselas, unas porque las ignoro y otras porque, aun sabiéndolas, no las escribiría" (246). Aseveración que resulta bastante interesante, puesto que permite advertir que todo texto, sea de ficción o no, se encuentra permeado por una fuerte carga ideológica, social y cultural de la que difícilmente puede despegarse. Todo relato es, en sí mismo, resultado de un proceso de conceptualización realizado desde unas cargas ideológicas particulares y un sistema socio-cultural bien específico, no siempre consciente, por supuesto.

Aclarado lo anterior, consideramos pertinente analizar las implicaciones que tiene el hecho de que las cartas que hemos revisado hasta aquí estén incluidas dentro de una totalidad mayor -la novela-, funcionando como un género intercalado o texto parásito. Como lo anota Roubaud \& Joly (1985), “el estudio de las cartas que se insertan en macrotextos no epistolares, y la relación que se establece entonces entre microtexto y macrotexto, sigue en una situación de relativo abandono" (103). Pocos son los trabajos dedicados a comprender cómo se entreteje la red de relaciones entre subgéneros como la carta (microtexto) y géneros literarios como la novela (macrotexto). No obstante, desde una perspectiva narratológica -que establece una clara distinción entre narrador (voz que narra) y focalización (punto de vista/ perspectiva que orienta el relato) - es posible que se den algunas luces en torno a tales cuestiones. Siguiendo a Lillo (2009):

[...] la carta como texto equivale al discurso del personaje, es decir, a la manifestación de un discurso de carácter mimético en la novela. [...] La inclusión de cartas en la novela supondría una reestructuración, una renovación de los géneros literarios y una dialogización de los géneros secundarios, y por lo tanto una debilitación de la composición monológica de la novela tradicional según lo afirmado por Bajtin [...]. Para éste, la carta es una forma de introducción y organización del plurilingüismo en la novela, y como tal instituye algo nuevo que se registra como género intercalado (73). 
Para entender lo anteriormente expuesto es necesario comprender algunos conceptos claves de la teoría bajtiniana como los de dialogismo, polifonía y plurilingüismo (o heteroglosia), y además, entender la distinción entre géneros discursivos primarios y secundarios que realiza el crítico ruso. Bajtín asume que, frente al discurso literario monológico que caracterizó buena parte de la Edad Media ${ }^{6}$, el dialogismo se asume como cualidad especialmente central en la constitución de las novelas modernas. Dialogismo, para Rodríguez (2008), "proviene de la palabra griega diálogo, que es la representación directa en el discurso novelístico del intercambio verbal entre dos o más personajes", e implica la presencia de múltiples voces en el discurso para caracterizar a los personajes con sus particulares formas de pensar, actuar, hablar e incluso pronunciar (revísese también heterofonía, heterología y heteroglosia). A esto Bajtin lo llama polifonía, uno de los elementos fundamentales del relato moderno.

La idea de la novela polifónica nos ayuda a comprender cómo las cartas insertas en la novela, sumadas al estilo directo predominante en ella, hacen parte de "otras" voces y discursos que implican un reconocimiento real de la otredad. El hecho de que el narrador principal de La pasión de Policarpa, no obstante, sea omnisciente, relativiza la posibilidad de establecer una narración polifónica stricto sensu, puesto que esta voz -que nos hace conocer las intimidades más recónditas de la conciencia de los personajes- limita el dialogismo y favorece la monofonía de la novela. En estos casos, es mejor hablar de una narración polifónica sui géneris en la que, a pesar de ser contados los acontecimientos por una entidad que lo sabe y conoce todo, se presenta una polifonía que cede la voz de forma directa al personaje (a través de diálogos, sueños y epístolas) para contrastar la versión del narrador con la de los personajes.

Es posible afirmar entonces, a la luz de las reflexiones anteriores, que el narrador en La pasión de Policarpa es omnisciente con focalización interna múltiple. En la narración epistolar, según Pimentel (1998), "cada personaje se convierte en el narrador, de tal suerte que la narración se focaliza alternativamente en cada uno de los corresponsales epistolares (focalización interna múltiple)" (99).

\footnotetext{
${ }^{6} \mathrm{El} \mathrm{monologismo} \mathrm{es} \mathrm{una} \mathrm{forma} \mathrm{de} \mathrm{discurso} \mathrm{en} \mathrm{la} \mathrm{cual} \mathrm{no} \mathrm{se} \mathrm{diferencia} \mathrm{entre} \mathrm{las}$ distintas voces participantes. La voz del narrador, de un príncipe y de un campesino aparecerán con un mismo estilo, una misma entonación, un mismo léxico. Esto caracteriza la literatura de la Edad Media, donde el sujeto cristiano presenta un monólogo donde el autor organiza por completo el mundo narrado, responde a la cultura oficial de la sociedad de manera ideológica, ubicándose dentro de las fuerzas oficiales o centrípetas de la sociedad (Rodríguez, 2008).
} 
Esto es, Barbarita Cuervo y Andrea Ricaurte, autoras de las cartas que se introducen a lo largo de la novela, son co-narradoras de la novela, posibilitando la confrontación ideológica al interior del relato. Esta cesión de la palabra permite múltiples lecturas de lo acontecido que -dado el caso- podrían modificar la historia novelada en tanto resultarán antagónicas o complementarias respecto a la voz del narrador.

Nótese, por ejemplo, la siguiente cita en la que Barbarita Cuervo, en una de sus cartas, nos dice qué sucede con los estados de fuerza que iban rumbo al Casanare cuando arrestaron a Alejo Zabaraín y a Francisco Arrellano: "Lo otro ya lo conoce usted pero a más quiero decir, para el cabal entendimiento de posteriores hechos, que los pliegos que el Cura Fernández tuvo la precaución de copiar fueron recogidos pocos días después por emisarios de Ramón Nonato Pérez y entregados después al general Santander" (323). Sólo aquí nos damos cuenta qué sucede con los documentos copiados por José María Arcos y, en esa medida, es posible entender por qué la labor que emprendieron los patriotas no fracasa: su esfuerzo sirvió para que muchos otros soldados patriotas tomaran decisiones estratégicas en cuanto a los senderos escogidos para avanzar en la guerra contra los godos. Este hecho únicamente se menciona en esta carta.

Ya aquí vemos con mucha más claridad cómo Barbarita Cuervo y Andrea Ricaurte logran construir una "historia otra" en la novela y desde las cartas que estas escriben. Propician el antagonismo y/o complementación de las distintas voces que tienen cabida en $L a$ pasión de Policarpa. A causa de estos personajes femeninos, y sus epístolas, podemos situarnos en una perspectiva microhistórica que concede especial importancia a eventos que son fundamentales para entender el proceder, las acciones y el devenir de naciones y pueblos enteros.

\section{Bibliografía}

Aínsa, F. (1997). “Invención literaria y 'reconstrucción' histórica en la nueva narrativa latinoamericana”. En: Kohut, K. (Ed.). La invención del pasado: La novela histórica en el marco de la posmodernidad. Madrid: Iberoamericana.

Badrán, P. (2010). La Pasión de Policarpa. Bogotá: Random House Mondadori, S.A.

Bajtín, M. (1993). Problemas de poética de Dostoievski. Fondo de Cultura Económica: México.

De Halicarnaso, H. (Editado por elaleph.com) (2000). Nueve libros de la historia. Recuperado de: http://www.dominiopublico.es/ 
libros/H/Herodoto/Herodoto $\% 20 \% 20$ Los $\% 20$ Nueve $\% 20$ Libros\%20de\%20la\%20Historia\%20-\%20Tomo\%20I.pdf.

Freyle, J. (1963). El carnero. Bogotá: Imprenta Nacional.

González y González, L. (1973). Hacia una teoría de la microhistoria. Discurso de sesión leído el 27 de marzo de 1973. Recuperado de: http://www.colmich.edu.mx/files/relaciones/057/pdf/ Luis\%20Gonzalez\%20y\%20Gonzalez.pdf.

Levi, G. (1990). La herencia inmaterial. Madrid: Nerea.

Lillo, M. (2009). “Cartas en/desde Berlín: Morir en Berlín de Carlos Cerda y El desierto de Carlos Franz". En: Acta Literaria № 39, II Semestre, 69-89.

Pimentel, L. A. (1998). El relato en perspectiva. México: Siglo XXI Editores.

Pons, M. C. (1999). "La novela histórica de fin de siglo XX: De inflexión literaria y gesto histórico, a retórica de consumo". En: Perfiles Latinoamericanos, número 15, Diciembre. México: Facultad Latinoamericana de Ciencias Sociales. Pp. 139-169.

Rodríguez, K. (2008). Dialogismo y polifonía. Recuperado de: http:// cristalotaku.wordpress.com/2008/10/06/dialogismo-ypolifonia/.

Roubaud, S. y Joly, M. (1985).Cartas son cartas. Apuntes sobre la carta fuera del género epistolar. Recuperado de: cvc.cervantes.es/literatura/ criticon/PDF/030/030_107.pdff. 